\title{
Synthesis and characterization of molecularly imprinted polymer for tramadol $\mathrm{HCl}$ using acryl amide and 2-hydroxyethyl meth acrylate as monomers
}

\author{
Ahmed Jalil Al-Safi, Yehya Kamal Al-Bayati ${ }^{*}$
}

Chemistry Department, College of Science, University of Baghdad, Al-Jadryia, Baghdad, Iraq

\begin{tabular}{|c|c|}
\hline ARTICLE INFO & ABSTRACT \\
\hline Received 18 December 2017 & \multirow[b]{3}{*}{$\begin{array}{l}\text { Four electrodes were synthesized based on molecularly imprinted polymers (MIPs). Two } \\
\text { MIPs were prepared by using tramadol hydrochloride (TRH) as the template, acryl amide } \\
\text { (AA) and 2-hydroxy ethyl meth acrylate (2-HEMA) as monomers, divinyl benzene as a } \\
\text { cross linker, and benzoyl peroxide as initiator, respectively. The same composition was } \\
\text { used to prepare non-imprinted polymers (NIPs), but without the template (Tramadol } \\
\text { hydrochloride). Different plasticizers were employed to prepare the membranes; tris } \\
\text { (ethyl hexyl) phosphate (TEHP), tri Butyl phosphate (TBP), di-octyl phthalate (DOP) } \\
\text { and nitrobenzene (NB) in PVC matrix. The electrode characteristics and properties were } \\
\text { studied, including: slope, detection limit, life time and linearity range. The results of } \\
\text { selectivity coefficient measurements using amino acids as interfering species showed no } \\
\text { effect on tramadol electrode response. The prepared electrodes were intended for use in } \\
\text { determining tramadol in pharmaceutical samples. }\end{array}$} \\
\hline Accepted & \\
\hline $\begin{array}{l}\text { Keywords: } \\
\text { molecularly imprinted } \\
\text { electrodes, } \\
\text { tramadol hydrochloride, } \\
\text { potentiometric method, } \\
\text { 2-HEMA, } \\
\text { AA monomers. }\end{array}$ & \\
\hline
\end{tabular}

\section{INTRODUCTION}

Tramadol hydrochloride (1R,2R)-2-[(dimethylamino) methyl]-(3methoxyphenyl)cyclohexan-1-ol is a drug acting on opiate and non-opiate receptors, and is used mainly in treating moderate to severe pain [1], disquiet and depression. It is also indicated for treating liver metabolization and renal excretion disorders which may lead to side effects, especially in those suffering from kidney or liver failure. Tramadol is a white crystalline powder freely soluble in water and in chloroform which is given by mouth or parenteral [2].

Tramadol hydrochloride content can be determined via several ways. The most recently developed method employs a modified carbon paste electrode [3], spectrophotometry<smiles>COc1cccc(C2(O)CCCC[C@H]2CN(C)C)c1</smiles>

Figure 1. Chemical structure of tramadol hydrochloride. The selective electrodes approach is an effective technique for determining tramadol content because it has fast response time, and is rapid and easy to use, is of low cost and selective

*Corresponding author
e-mail: yahyaalbayti@yahoo.com

[4-7], HPLC [7-9], GC [10], LC-MS/MS [11], capillary electrophoresis [12], voltammetry [13] and potentiometric [14-19].

The potentiometric sensor technique utilizes PVC membrane electrodes that are widely available and widely employed for the analysis of drugs and ionic species [20-28]. There are a variety drugs that are determined by the liquid selective electrode approach wherein MIPs being are used as recognition membranes. Among these are ibuprofen [29], warfarin [30], phenytoin [31] and metronidazole benzoate [32].

In this research, a polymerization process was used to prepare molecularly imprinted polymers (MIPs) for tramadol as the template and acrylamide and 2-hydroxy ethyl methacrylate as monomers, divinyl benzene as the cross linker, benzoyl peroxide as the initiator. In this study, different plasticizers were employed to construct electrode membranes which were then assessed in the task of determining tramadol in pharmaceutical samples.

\section{EXPERIMENTAL}

\section{Preparation of MIP}

For the preparation of the first tramadol hydrochloride molecularly imprinted polymer (TRH-MIP1), $0.569 \mathrm{mmol}$ 
$(0.15 \mathrm{~g})$ of tramadol $\mathrm{HCl}$ was mixed with $1.803 \mathrm{mmol}$ $(0.475 \mathrm{~g})$ acryl amide as the monomer. After this, 21.116 mmol $(5.565 \mathrm{~g})$ divinyl benzene was added to the solution as the cross linker, followed by $(0.05 \mathrm{~g})$ benzoyl peroxide as the initiator. All these materials were subsequently dissolved in $3 \mathrm{~mL}$ mixture of acetonitrile and chloroform. The second tramadol molecularly imprinted polymer (TRH-MIP2) was created by mixing together $0.301 \mathrm{mmol}(0.0795 \mathrm{~g})$ tramadol hydrochloride, $2.277 \mathrm{mmol}(0.6 \mathrm{~g})$ 2-hydroxyethyl meth acrylate as the monomer, $4.935 \mathrm{mmol}$ (1.3) divinyl benzene as the cross linker and $(0.05 \mathrm{~g})$ benzoyl peroxide as the initiator. The product was then dissolved in $2 \mathrm{~mL}$ mixture of acetonitrile and chloroform, and the mixture was stirred for 5 minutes to obtain a homogenous solution. Afterwards, the gas N2 was passed through the solution for 30 minutes to remove oxygen from it, and the solution was placed in a water path at $65^{\circ} \mathrm{C}$. When the reaction was complete, the molecularly imprinted polymer became hard, and, after the polymerization process, the polymer was dried and crushed to obtain it as particles. Finally, these particles was sonicated in $\mathrm{CH}_{3} \mathrm{OH} / \mathrm{CH}_{3} \mathrm{COOH}(18: 2 \mathrm{v} / \mathrm{v})$ to remove the template from the MIP. The particles size of TRH- MIP1 and TRH-MIP 2 were between ( $53 \mu \mathrm{m}$ and $125 \mu \mathrm{m})$, respectively.

The preparation of non-molecularly imprinted polymers was done by way of the same procedure, using the same substances and under the same conditions as in the preparation of TRH-MIP1 and TRH-MIP2, but without the tramadol hydrochloride. To fabricate the electrode, a PVC tube (1-2 cm long) was flattened and polished by placing it on a glass plate and soaking it with THF. The membrane was then cut similar to the external diameter of the PVC tubing and pasted on the polished end. The other end of this was linked with an $\mathrm{Ag}-\mathrm{AgCl}$ electrode. medical appliances (IRAQ-SDI-Samara). Coltra tablets (50 mg) (BRAWN, Haryana, India) were purchased from local pharmacies.

2. Plasticizers, tris (2-ethyl hexyl) phosphate (TEHP) (97.0\% purity), tri-butyl phosphate (TBP) (99.0\% purity), di-octyl phthalate (DOP) (99.5\% purity), nitrobenzene (NB) $(99.4 \%$ purity) were purchased from Sigma Aldrich. Other chemicals and reagents materials were obtained from Fluka, BDH and Sigma Aldrich.

\section{Preparation of standard solutions}

1. $50 \mathrm{~mL}$ of stock standard solution of $0.1 \mathrm{M}$ tramadol hydrochloride was prepared by dissolving $1.317 \mathrm{~g}$ of standard tramadol hydrochloride in bi-distilled water. The other tramadol solutions ranged from $10^{-6}-10^{-2} \mathrm{M}$ in $100 \mathrm{~mL}$, and came from the stock solution of tramadol.

2. $100 \mathrm{~mL}$ of each amino acid solution was prepared from $10^{-6}$ to $10^{-2} \mathrm{M}$ of a stock solution of $0.1 \mathrm{M}$ amino acid.

\section{Synthesis of membrane molecularly imprinted polymers}

A tramadol- $\mathrm{HCl}$ membrane was immobilized into a PVC tube as previously describe in reference $[33,34]$. Herein, $0.04 \mathrm{~g}$ of TRH-MIP was mixed with $0.8 \mathrm{~g}$ plasticizer, either: TEHP (electrode A1), TBP (electrode A2), DOP (electrode $\mathrm{B} 1$ ), and NB (electrode B2). Following this, $0.34 \mathrm{~g}$ of PVC powder was scattered on $7 \mathrm{~mL}$ of tetrahydrofuran and stirred until a homogenous and clear viscous solution was acquired. The mixture was cast into a glass ring 30-35 mm diameter and unwound on a glass plate, with a ribbon of filter being positioned on top of the glass. The solvent was then allowed to evaporate at room temperature for more than 24 hours at least. The thickness of the obtained membrane was about

\section{Instruments}

In this work, we use an analyzer (WTW model, Germany), pH meter (WTW model pH 720, Germany) and a saturated calomel electrode (Gallenkamp, USA). The tramadol HCl-MIP electrodes were fabricated as previously described, in the laboratory. All potentiometric measurements was made at room temperature. For research purposes, the tramadol hydrochloride-MIP electrode was combined with an $\mathrm{Ag}-\mathrm{AgCl}$ electrode, while $0.1 \mathrm{M}$ of tramadol hydrochloride was used as internal solution, the electrode being soaked with this for at least 2 hours before use.

\section{Materials and chemicals}

1. Tramadol hydrochloride standard was obtained as a gift from the state company of drug and food industries and

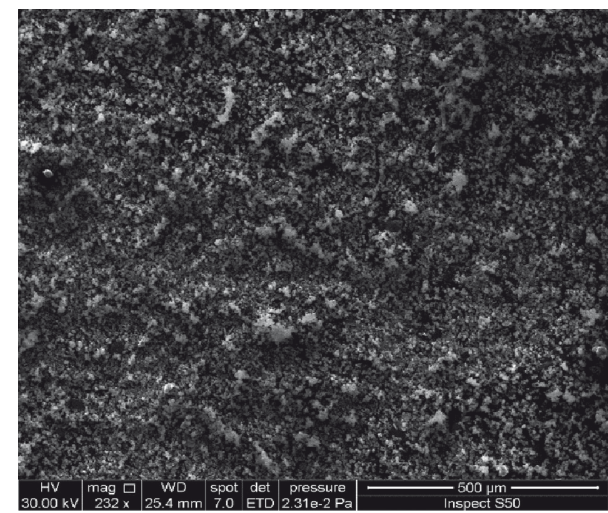

Figure 2a. SEM for MIP1 before washing

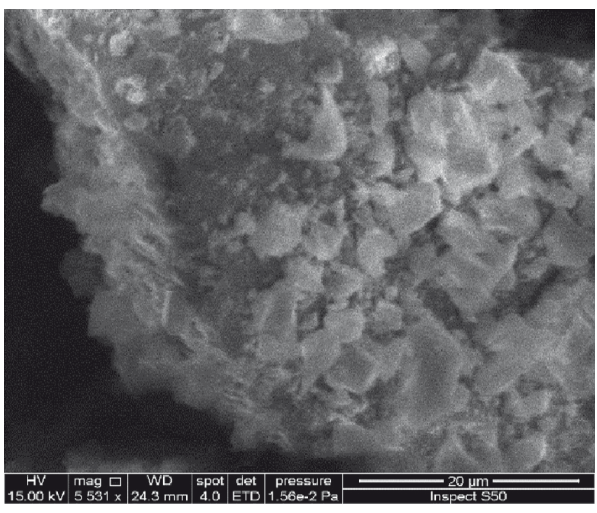

Figure 3a. SEM for MIP2 before washing

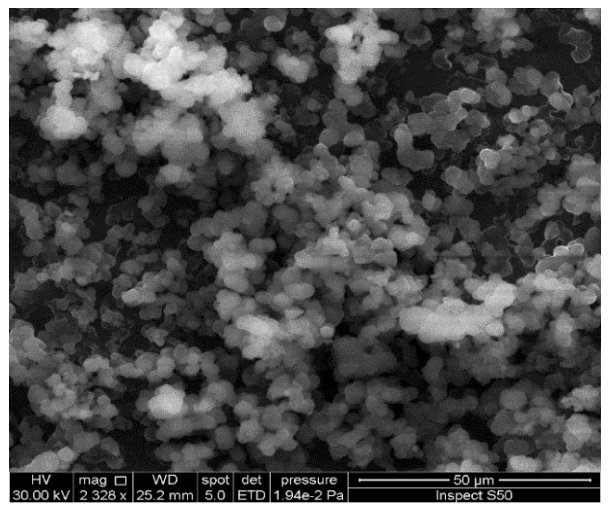

Figure $2 \boldsymbol{b}$. SEM for MIP1 after washing

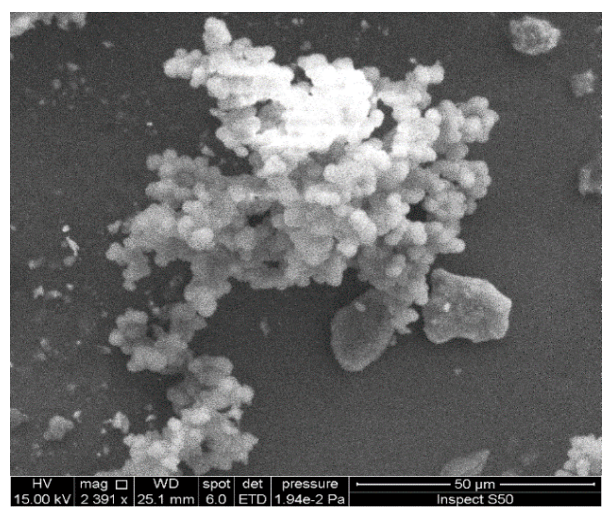

Figure 3b. SEM for MIP2 after washing 
(0.4-0.7) $\mathrm{mm}$. This size of membrane was considered adequate for electrode preparation.

\section{Scanning Electron Microscope (SEM)}

The SEM can be used to get an idea about the size, geometry and pore surface distribution of the membranes. SEM analysis indicates that molecular imprinted polymer in surface and in cross-section, had a highly ordered and regular pore structure which serves as the sites of interaction. Several papers have shown that a molecular imprinted membrane of this type recognizes the template molecule effectively and transports it with good efficiency due to the type and quality of the porous structures.

As shown by SEM, the morphology of MIP before and after washing is displayed in Figure 2a, 2b and Figure 3a, $3 \mathrm{~b}$. Herein, it can be seen that micro emulsion polymerization gives very small particles size around (4032-8064) nm for acryl amide (AA) polymer and (6923-9230) $\mathrm{nm}$ for 2-hydroxyethyl meth acrylate (2-HEMA) polymer.

\section{Preparation of pharmaceutical samples}

The drug tablets were ground to powder by using pestle and mortar. Subsequently, a required weight of the powder was used to prepare $100 \mathrm{~mL}$ solutions. Here, a certain amount of powder was dissolved in acetonitrile $\left(\mathrm{CH}_{3} \mathrm{CN}\right)$ and stirred by magnetic stirrer for 30 minutes to completely dissolve the powder. The solution was completed to 100 $\mathrm{mL}$ by water to prepare $5 \times 10^{-3} \mathrm{M}$ and $5 \times 10^{-4} \mathrm{M}$ tramadol solutions.

\section{RESULTS AND DISCUSSION}

Several experiments were done to find out the optimal ratios of drug: monomer: cross linker for preparing molecularly imprinted polymers and non-imprinted polymers. The best ratios for forming MIPs and NIPs which give suitable performance characteristics are presented in Table 1.

Table 1. Different ratios of (D: M: C) and progeny used in the synthesis of MIPs and NIPs for (TRH)

\begin{tabular}{|c|c|c|c|c|c|c|c|}
\hline \multirow{2}{*}{$\begin{array}{l}\text { No. } \\
\text { of } \\
\text { MIP }\end{array}$} & \multirow{2}{*}{ Ratio } & Drug & Monomer & $\begin{array}{l}\text { Cross } \\
\text { linker }\end{array}$ & Initiator & \multirow{2}{*}{ Solvent } & \multirow{2}{*}{ Result } \\
\hline & & (TR) & $(A A)$ & (DVB) & (BPO) & & \\
\hline \multirow{2}{*}{ MIP1 } & $\%$ & 6.13 & 7.97 & 85.88 & - & \pm 5 & Pile \\
\hline & $\mathrm{mmol}$ & 0.3 & 0.39 & 4.2 & 0.24 & $\mathrm{mLC}_{2} \mathrm{H}_{3} \mathrm{~N}$ & gel \\
\hline \multirow{2}{*}{ MIP1 } & $\%$ & 2.56 & 46.15 & 51.28 & - & \pm 5 & Pile \\
\hline & $\mathrm{mmol}$ & 0.5 & 9 & 10 & 0.127 & $\mathrm{mLC}_{2} \mathrm{H}_{3} \mathrm{~N}$ & gel \\
\hline \multirow{2}{*}{ MIP1 } & $\%$ & 4 & 16 & 80 & - & \pm 5 & Pile \\
\hline & $\mathrm{mmol}$ & 0.5 & 2 & 10 & 0.2 & $\mathrm{mLC}_{2} \mathrm{H}_{3} \mathrm{~N}$ & gel \\
\hline \multirow{2}{*}{ MIP1 } & $\%$ & 1.14 & 13.366 & 85.49 & - & \pm 5 & White \\
\hline & $\mathrm{mmol}$ & 0.57 & 6.682 & 42.74 & 0.2 & $\mathrm{mLC}_{2} \mathrm{H}_{3} \mathrm{~N}$ & rigid \\
\hline \multirow{2}{*}{ NIP 1} & $\%$ & & 13.52 & 86.47 & - & \pm 5 & White \\
\hline & $\mathrm{mmol}$ & - & 6.682 & 42.74 & 0.2 & $\mathrm{mLC}_{2} \mathrm{H}_{3} \mathrm{~N}$ & rigid \\
\hline \multirow{3}{*}{ MIP2 } & & (TR) & (2HEMA) & (DVB) & (BPO) & & \\
\hline & $\%$ & 1.14 & 13.366 & 85.49 & - & \pm 5 & Pile \\
\hline & $\mathrm{mmol}$ & 0.57 & 6.682 & 42.74 & 0.2 & $\mathrm{mLCHCL}_{3}$ & $\begin{array}{l}\text { gel } \\
\text { gel }\end{array}$ \\
\hline \multirow{2}{*}{ MIP2 } & $\%$ & 12.73 & 27.53 & 59.72 & 2 & \pm 5 & Pile \\
\hline & $\mathrm{mmol}$ & 2.133 & 4.61 & 10 & 0.2 & $\mathrm{mLCHCL}_{3}$ & gel \\
\hline \multirow{2}{*}{ MIP2 } & $\%$ & 2.01 & 30.96 & 67.02 & - & \pm 5 & yellow \\
\hline & $\mathrm{mmol}$ & 0.301 & 4.61 & 9.98 & 0.2 & $\mathrm{mLCHCL}_{3}$ & rigid \\
\hline \multirow{2}{*}{ NIP 2} & $\%$ & - & 31.59 & 68.4 & - & \pm 5 & yellow \\
\hline & $\mathrm{mmol}$ & & 4.61 & 9.98 & 0.2 & $\mathrm{mLCHCL}_{3}$ & rigid \\
\hline
\end{tabular}

All ratios of MIPs and NIPs were prepared in a water bath at $60-80^{\circ} \mathrm{C}$.

Table 2. The most identified peaks of FT-IR spectra for TRHimprinted polymer using acryl amide (AA) as a monomer

\begin{tabular}{|c|l|c|c|c|}
\hline No. & \multicolumn{1}{|c|}{ Functional Group } & TRH & $\begin{array}{c}\text { TRH-MIP (AA) } \\
\text { before template } \\
\text { removal }\end{array}$ & $\begin{array}{c}\text { TRH-MIP (AA) } \\
\text { After template } \\
\text { removal }\end{array}$ \\
\hline 1 & O-H str. $\left(\mathrm{cm}^{-1}\right)$ & 3305 & 3365 & ------- \\
\hline 2 & C-H aliphatic. $\left(\mathrm{cm}^{-1}\right)$ & 2931,2860 & 2920,2860 & 2921,2856 \\
\hline 3 & C-H aromatic. $\left(\mathrm{cm}^{-1}\right)$ & 3068 & 3050 & 3043 \\
\hline 4 & C=C str. $\left(\mathrm{cm}^{-1}\right)$ & 1606 & 1604 & 1600 \\
\hline 5 & C=O str.amid. $\left(\mathrm{cm}^{-1}\right)$ & ----- & 1674 & 1679 \\
\hline 6 & C=C str.olefin $\left(\mathrm{cm}^{-1}\right)$ & ------ & 1604 & 1629 \\
\hline 7 & C-O str.ether.(cm-1) & 1047 & 1060 & ----- \\
\hline 8 & Out-of plane-para-sub & ----- & 815 & 835 \\
\hline 9 & Out-of plane-meta-sub & 781,703 & 815,707 & ----- \\
\hline
\end{tabular}

The Fourier transmission infrared spectrometry (FTIR) spectra of leached and unleashed tramadol hydrochloride imprinted polymers MIP and NIP using acryl amide as monomer were recorded in the range of $400-4000 \mathrm{~cm}^{-1}$ by the $\mathrm{KBr}$ pellet method. These are listed in Table 2.

The FTIR spectrum of TRH and TRH-MIP and after template removal showed a band at 3305 and $3365 \mathrm{~cm}^{-1}$ for hydroxyl group stretching, at 1047 and $1060 \mathrm{~cm}^{-1}$ for carbonyl ether group stretching and at 781,703,815 and $707 \mathrm{~cm}^{-1}$ for meta substitution, but disappearance at the TRH-MIP FTIR spectrum. FTIR spectrum of TRH-MIP after template removal showed a band at $1679 \mathrm{~cm}^{-1}$ for carbonyl amide group stretching, $1629 \mathrm{~cm}^{-1}$ for olefin group stretching and $835 \mathrm{~cm}^{-1}$ for para substitution.

All of the above indicate that the template was synthesized and the drug was removed from the polymer.

The Fourier transmission infrared spectrometry (FTIR) spectra of leached and unleashed tramadol hydrochloride imprinted polymers MIP and NIP using 2-Hydroxyethyl methacrylate as a monomer were recorded and listed in Table 3 .

Table 3. The most identified FT-IR spectra peaks for the TRH-imprinted polymer, using 2-Hydroxyethyl methacrylate (2-HEMA) as a functional monomer

\begin{tabular}{|c|l|c|c|c|}
\hline No. & \multicolumn{1}{|c|}{ Functional Group } & TRH & $\begin{array}{c}\text { TRH-MIP } \\
(2-H E M A) \\
\text { before template } \\
\text { removal }\end{array}$ & $\begin{array}{c}\text { TRH-MIP } \\
(2-H E M A) \\
\text { After template } \\
\text { removal }\end{array}$ \\
\hline 1 & O-H str. $\left(\mathrm{cm}^{-1}\right)$ & 3305 & 3477,3423 & 3442 \\
\hline 2 & C-H aliphatic. $\left(\mathrm{cm}^{-1}\right)$ & 2931,2860 & 2929 & 2925,2856 \\
\hline 3 & C-H aromatic. $\left(\mathrm{cm}^{-1}\right)$ & 3068 & 3083 & 3002 \\
\hline 4 & C=C str. $\left(\mathrm{cm}^{-1}\right)$ & 1606 & 1604 & 1600 \\
\hline 5 & C=O str.ester $\left(\mathrm{cm}^{-1}\right)$ & ----- & 1714 & 1724 \\
\hline 6 & C-O str.ether. $\left(\mathrm{cm}^{-1}\right)$ & ----- & 1081 & 1078 \\
\hline 7 & C=C str.olefin (cm-1) & ----- & 1629 & 1629 \\
\hline 8 & Out-of plane-para-sub & ----- & 815 & 837 \\
\hline
\end{tabular}

The FTIR spectrum of TR-MIP after template removal showed a band at $1078 \mathrm{~cm}^{-1}$ for carbonyl ether group stretching, at $1629 \mathrm{~cm}^{-1}$ for olefin group stretching and at $837 \mathrm{~cm}^{-1}$ for para substitution. It also showed disappearance at the TR FTIR spectrum. 


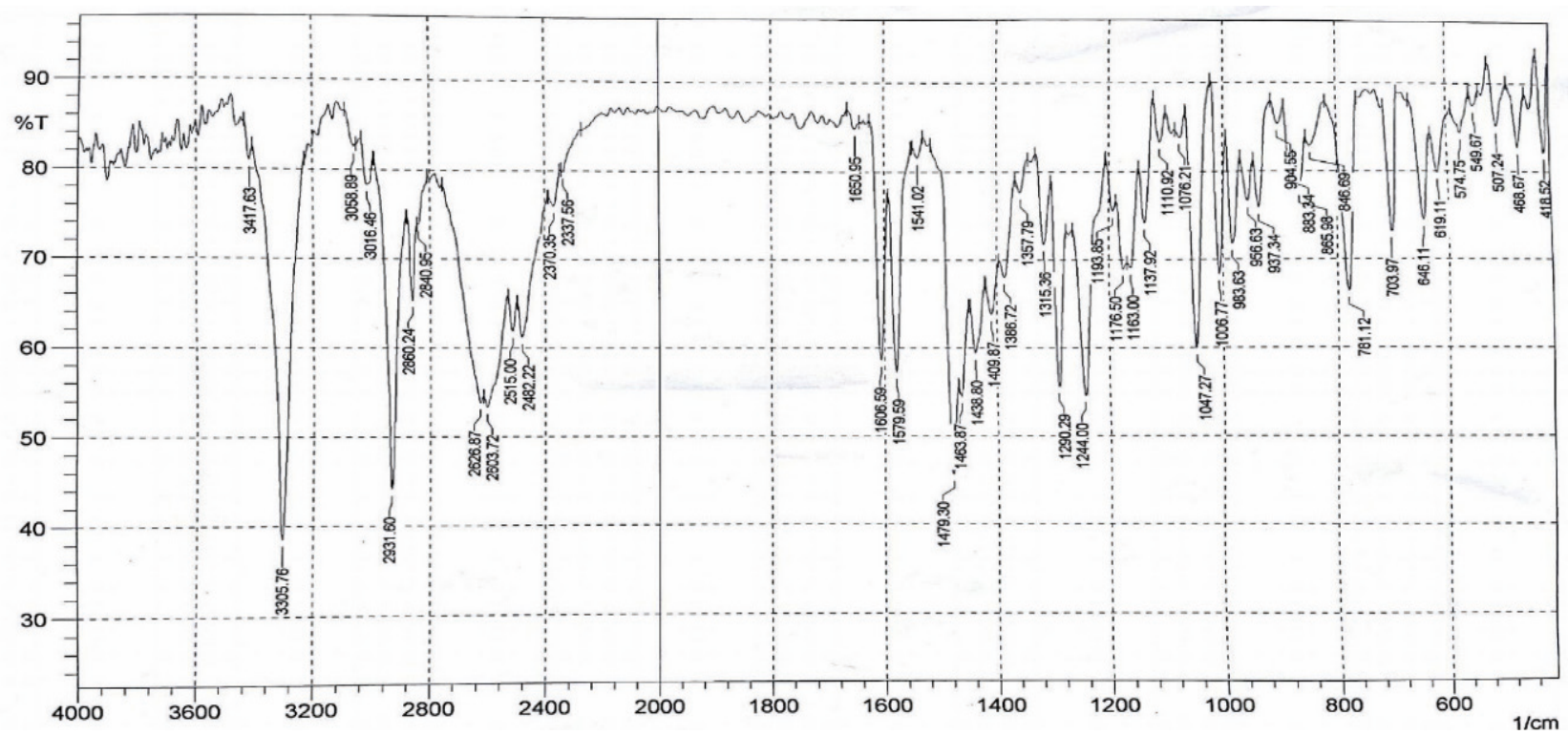

Figure 4. FTIR of (TRH) drug

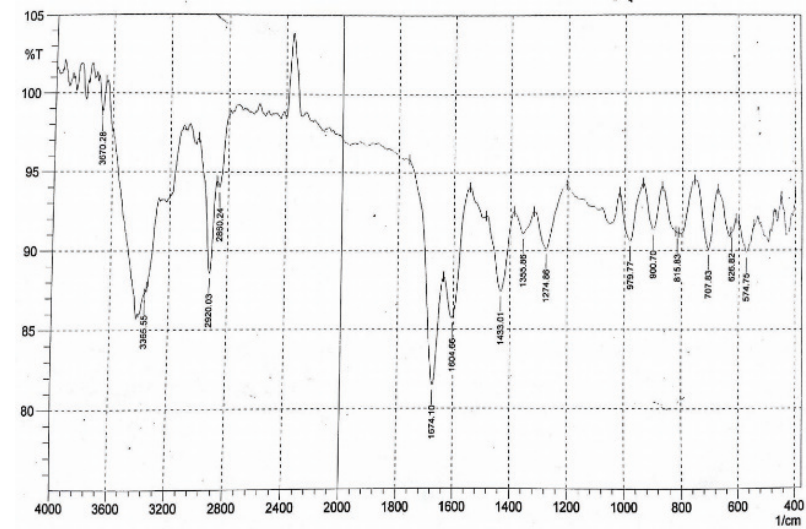

Figure 5. FTIR of TRH-MIP (AA) before the removal of TRH

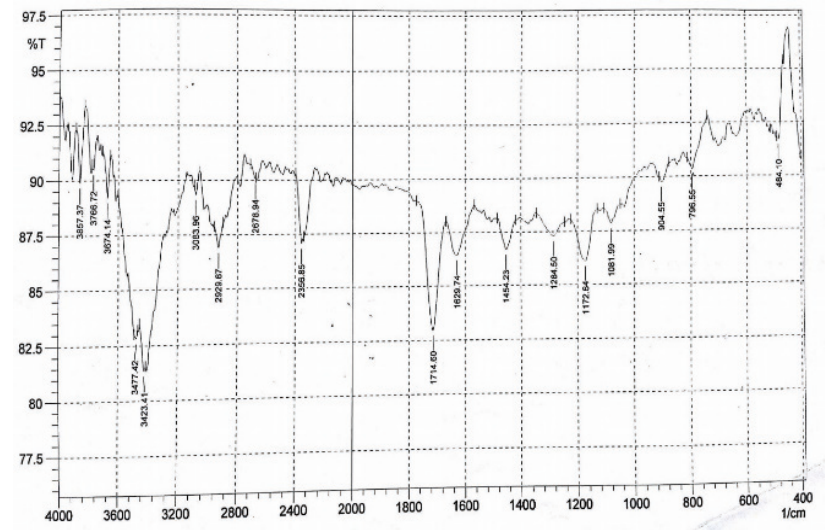

Figure 7. FTIR of TRH-MIP (2-HEMA) before the removal of TRH

All of the above indicate that the template was synthesized and the drug was removed from the polymer.

The plasticizer is an important component for membrane selective electrode and must have compatibility with the polymer and other membrane constituents to provide a homogeneous environment for the membrane. Four types of MIPs membranes were prepared with different types of plasticizers in order to study the viscosity, permeability and ability to avoid leaching of the plasticizer and MIP from the electrode (which otherwise would affect the electrode

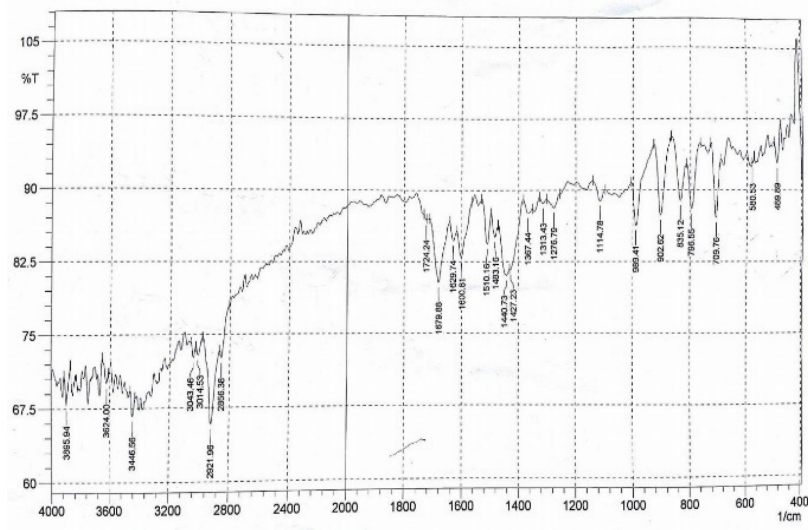

Figure 6. FTIR of TRH-MIP (AA) after the removal of TRH

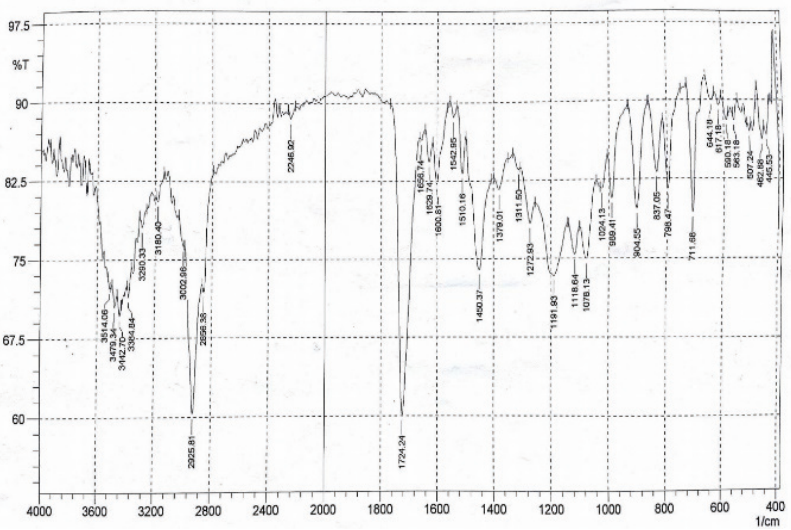

Figure 8. FTIR of TRH-MIP (2-HEMA) after the removal of TRH

performance over time). The plasticizers are: tris (2-ethyl hexyl) phosphate ( TEHP), tri- butyl phosphate ( TBP), di-octyl phthalate (DOP) and nitrobenzene (NB). The characteristics and specification of each electrode parameter were studied based on TRH-MIP1 (A1, A2 membranes) and TRH-MIP2 (B1, B2 membranes). The examined electrode parameters are: linearity range, correlation coefficients, detection limit, and life time, respectively. The results obtained are shown in Table 4, while their calibration curves are shown in Figure 9. 
Table 4. Characteristics of the tramadol HCl-MIP electrode based on different functional monomers and plasticizers

\begin{tabular}{|l|c|c|c|c|}
\hline $\begin{array}{c}\text { Membrane } \\
\text { composition }\end{array}$ & $\begin{array}{c}\text { TRH-MIP1+ } \\
\text { TEHP (A1) }\end{array}$ & $\begin{array}{c}\text { TRH-MIP1+ } \\
\text { TBP (A2) }\end{array}$ & $\begin{array}{c}\text { TRH-MIP2+ } \\
\text { DOP (B1) }\end{array}$ & $\begin{array}{c}\text { TRH-MIP2+ } \\
\text { NB (B2) }\end{array}$ \\
\hline Slope (mV/decade) & 33.15 & 32.09 & 16.17 & 30.21 \\
\hline Linearity range (M) & $10^{-2}-10^{-5}$ & $10^{-3}-10^{-6}$ & $10^{-2}-10^{-5}$ & $10^{-3}-10^{-6}$ \\
\hline $\begin{array}{l}\text { Correlation } \\
\text { coefficient }\end{array}$ & 0.9813 & 0.9896 & 0.9869 & 0.9940 \\
\hline Detection limit (M) & $3 \times 10^{-6}$ & $1 \times 10^{-6}$ & $1 \times 10^{-6}$ & $2 \times 10^{-6}$ \\
\hline Life time (day) & 16 & 12 & 7 & 4 \\
\hline
\end{tabular}

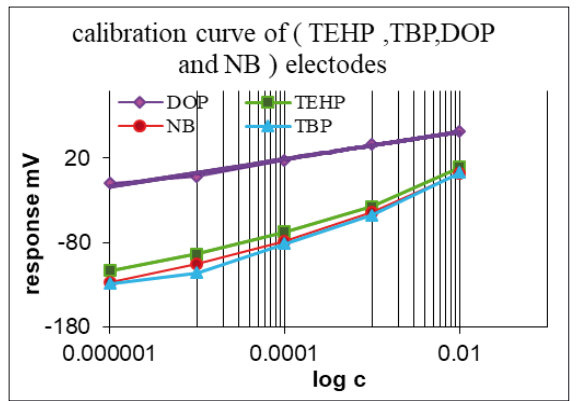

Figure 9. Calibration curve for TRH-MIP1 and TRH-MIP2 membrane electrodes

The three electrodes A1, A2, and B2 gave Nernstian slopes of $33.15,32.09$, and $30.21 \mathrm{mV} /$ decade, respectively. These slopes indicate that the drug interacts with the polymer via two covalent bonds. Electrode B1, however, shows a non-Nernstian slope of $16.17 \mathrm{mV} /$ decade. The low slope of $16.17 \mathrm{mV} /$ decade revealed by electrode TRH-MIP2+DOP is due to the incompatibility of the DOP plasticizer with the species of the membrane (the monomer). This brought about a leaching of the plasticizer from the membrane into the external solution. As the life time of electrodes A1 and $\mathrm{A} 2$ as given in Table 4 are longer than that of electrodes B1 and $\mathrm{B} 2$, therefore, electrodes $\mathrm{A} 1$ and $\mathrm{A} 2$ are better for use in the determination of tramadol content in pharmaceutical samples.

All experiments for the calibration of NIP electrodes gave a constant potential for the tramadol solutions ranging from $10^{-1}$ to $10^{-6} \mathrm{M}$.

\section{Effect of pH on electrode response}

Three concentrations of tramadol solution $\left(5 \times 10^{-3}\right.$, $5 \times 10^{-4}$ and $5 \times 10^{-5}$ ) were used to study the effect of $\mathrm{pH}$ on electrode response. The electrode potential as measured for the tested solutions has $\mathrm{pH}$ ranging from 1 to 10 . The low and high $\mathrm{pH}$ were fixed by using hydrochloric acid $(0.1 \mathrm{M}, 1 \mathrm{M})$ and/or ammonium hydroxide $(0.1 \mathrm{M}, 1 \mathrm{M})$, respectively. The results obtained by adding the appropriate volume of $\mathrm{HCl} / \mathrm{NH}_{4} \mathrm{OH}$ are shown in Table 5, while the typical plot for electrode A1 is shown in Figure 10. At high acidity of less than 4 , the tramadol begins to hydrolyzed and the electrode responds to hydrogen ions. The best $\mathrm{pH}$ for calibrating the electrodes is, thus, between 4 to 8 .
Table 5. Working $\mathrm{pH}$ range for tramadol hydrochloride selective electrodes

\begin{tabular}{|c|c|c|c|c|c|}
\hline \multirow{2}{*}{$\begin{array}{c}\text { Number and } \\
\text { composition of MIPs }\end{array}$} & Membranes & \multirow{2}{*}{$\begin{array}{c}\text { Membrane } \\
\text { composition }\end{array}$} & \multicolumn{3}{|c|}{$\mathrm{pH}$ range } \\
\cline { 4 - 6 } $\begin{array}{c}\text { MIP1 } \\
\text { TR+AA+DVB }\end{array}$ & $\mathrm{A} 1$ & $\begin{array}{c}\text { TR-MIP1 } \\
+ \text { TEHP }\end{array}$ & $4-8.5$ & $4.5-9$ & $4-8$ \\
\cline { 2 - 6 } & $\mathrm{A} 2$ & $\begin{array}{c}\text { TR-MIP1 } \\
+ \text { TBP }\end{array}$ & $4-7.5$ & $2.5-7.5$ & $4-8$ \\
\hline $\begin{array}{c}\text { MIP2 } \\
\text { TR+2-HEMA + DVB }\end{array}$ & $\mathrm{B} 1$ & $\begin{array}{c}\text { TR- } \\
\text { MIP2+DOP }\end{array}$ & $3-8$ & $4-7.5$ & $3-8$ \\
\cline { 2 - 6 } & $\mathrm{B} 2$ & $\begin{array}{c}\text { TR-MIP2 } \\
\text { +NB }\end{array}$ & $4.5-8.5$ & $4.5-8$ & $5.5-9.5$ \\
\hline
\end{tabular}

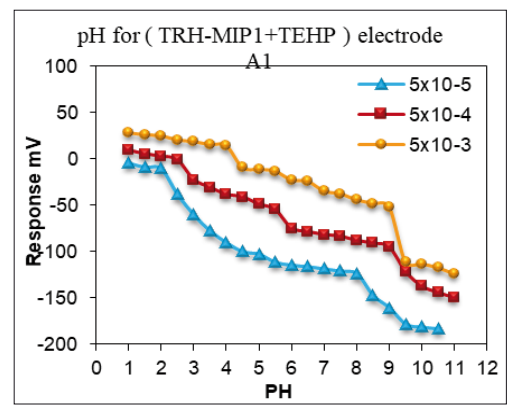

Figure 10. Effect of $\mathrm{pH}$ on the tramadol hydrochloride ((TRHMIP2+DOP (A1)) electrodes at concentrations $5 \times 10^{-3}, 5 \times 10^{-4}$ and $5 \times 10^{-5}$

\section{Interference study}

For calculating the selectivity coefficient measurement, we used the separate solution method. The procedure is to plot the calibration curve for tramadol solutions ranging from $10^{-1}$ to $10^{-6} \mathrm{M}$, then to plot calibration curves for the same concentrations $\left(10^{-1}\right.$ to $\left.10^{-6} \mathrm{M}\right)$ of amino acid, and subsequently apply the following equation to calculate the selectivity coefficient.

\section{$\log K p o t=[(E B-E A) /(2.303 R T / z F)]+(1-z A / z B) \log$ aA}

EA, EB; zA, zB; and aA, represents the potentials, charge numbers and activities for the primary $A$ and interfering $B$ ions, respectively, at $\mathrm{aA}=\mathrm{aB}$. Interfering species of amino acids: asparagine, arginine, glycine, and tryptophan were employed in order to simulate the effect of the amino acid when a patient co-self-administers tablets containing the aforementioned amino acids with a tablet of tramadol. The interference depends upon the ability of the amino acid to fit in the cavity of the polymer. The selectivity coefficients of the amino acids using electrodes based on TRH-MIP1TEHP are listed in Table 6. Because of the obtained low selectivity coefficients values, the results indicate that there

Table 6. Selectivity coefficients for (TRH-MIP1+TEHP) electrode at different concentrations of tramadol hydrochloride

\begin{tabular}{|c|c|c|c|c|c|c|c|c|}
\hline \multirow{4}{*}{$\begin{array}{c}\text { Conc. } \\
\text { (M) }\end{array}$} & \multicolumn{8}{|c|}{ Concentrations of tramadol hydrochloride $(\mathrm{M})$ : Concentrations of interference ions $(\mathrm{M})$} \\
\hline & \multicolumn{8}{|c|}{ Interfering ions } \\
\hline & \multicolumn{2}{|c|}{ Asparagine } & \multicolumn{2}{|c|}{ Arginine } & \multicolumn{2}{|c|}{ Glycine } & \multicolumn{2}{|c|}{ Tryptophan } \\
\hline & $\begin{array}{c}\text { EB } \\
(\mathrm{mV})\end{array}$ & $\mathrm{KA}, \mathrm{B}$ & $\begin{array}{c}\mathrm{EB} \\
(\mathrm{mV})\end{array}$ & $\mathrm{KA}, \mathrm{B}$ & $\begin{array}{c}\mathrm{EB} \\
(\mathrm{mV})\end{array}$ & $\mathrm{KA}, \mathrm{B}$ & $\begin{array}{c}\mathrm{EB} \\
(\mathrm{mV})\end{array}$ & $\mathrm{KA}, \mathrm{B}$ \\
\hline $10-2$ & -74.2 & $4.7336 \times 10^{-3}$ & -98.1 & $9.0446 \times 10^{-4}$ & -101.9 & $6.9519 \times 10^{-4}$ & -114.2 & $2.9661 \times 10^{-4}$ \\
\hline $10-3$ & -97.6 & $2.3765 \times 10^{-2}$ & -109.4 & $1.0497 \times 10^{-2}$ & -128.1 & $2.8751 \times 10^{-3}$ & -119.9 & $5.0730 \times 10^{-3}$ \\
\hline $10-4$ & -107.4 & $2.0196 \times 10^{-1}$ & -129 & $4.5252 \times 10^{-2}$ & -136.4 & $2.7107 \times 10^{-2}$ & -129.3 & $4.4322 \times 10^{-2}$ \\
\hline $10-5$ & -134.9 & $1.0317 \times 10^{-1}$ & -124.6 & $2.1053 \times 10^{-1}$ & -149.1 & $3.8589 \times 10^{-2}$ & -132.6 & $1.2098 \times 10^{-1}$ \\
\hline $10-6$ & -141.1 & $6.0738 \times 10^{-1}$ & -139.8 & $6.6459 \times 10^{-1}$ & -155.7 & $2.2098 \times 10^{-1}$ & -146.9 & $4.0646 \times 10^{-1}$ \\
\hline
\end{tabular}


is no interference of these amino acids. A typical selectivity coefficient plot of these amino acids based on use of electrode TRH-MIP1-TBP is shown in Figure 11.

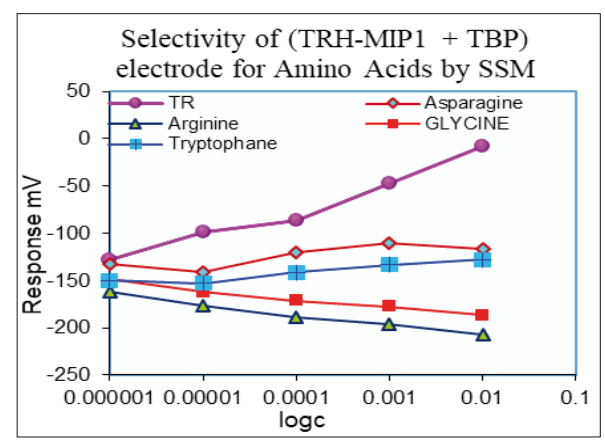

Figure 11. Selectivity coefficient of TRH-MIP $1+$ TBP electrodes with amino acids

\section{Analysis of tramadol in commercial pharmaceutical tablets}

Three methods were used for measuring the tramadol in pharmaceutical tablets: direct, the single method and the standard addition method. The method performances were checked by applying them to synthetic tramadol solutions. The concentrations of synthetic tramadol used were $5 \times 10^{-3}$ and $5 \times 10^{-4} \mathrm{M}$, and the results are listed in Table 7 . Herein, excellent results were obtained, the percent recovery ranged from 88-102 with low values of errors. A typical plot for the standard addition method is shown in Figure 12. This used electrode TRH-MIP2-DOP and $5 \times 10^{-3} \mathrm{M}$ and $5 \times 10^{-3} \mathrm{M}$ concentrations of tramadol. The results indicate the prepared electrodes were extremely suitable for determining tramadol content in commercial tablets.
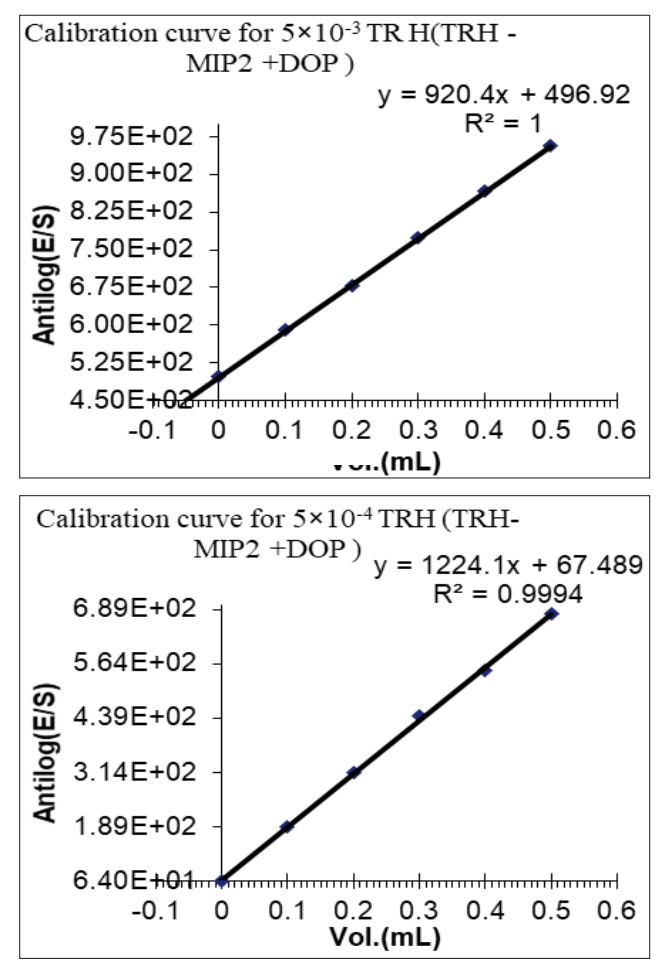

Figure 12. Standard addition method for determining tramadol hydrochloride solution content $\left(5 \times 10^{-3}\right.$ and $\left.5 \times 10^{-4}\right)$ by MSA, using the TRH-MIP2+DOP electrode
Table 7. Determination of tramadol hydrochloride in synthetic solutions of tramadol

\begin{tabular}{|c|c|c|c|c|c|}
\hline $\begin{array}{c}\text { Electrode NO. } \\
\text { and composition }\end{array}$ & & heasurer & th by usin & SE met & \\
\hline & & Stan & rd sample & $5 \times 10^{-3}$ & \\
\hline & Parameter & RSD\% & RC\% & RE\% & Con. found \\
\hline & Direct & 0.69 & 98.62 & -1.38 & $4.9309 \times 10^{-3}$ \\
\hline & SAM & 0.72 & 98.92 & -1.08 & $4.9459 \times 10^{-3}$ \\
\hline TRH-MIP1+TEHP & MSA & - & 99.05 & -0.95 & $4.9527 \times 10^{-3}$ \\
\hline & & Stan & rd sample & $5 \times 10^{-4}$ & \\
\hline & Parameter & RSD\% & RC\% & $\mathrm{RE} \%$ & Con. found \\
\hline & Direct & 1.38 & 98.28 & -1.72 & $4.9140 \times 10^{-4}$ \\
\hline & SAM & 1.9 & 102.85 & 2.85 & $5.1423 \times 10^{-4}$ \\
\hline & MSA & - & 98.85 & -1.15 & $5.0268 \times 10^{-4}$ \\
\hline & & Stan & rd sample & $5 \times 10^{-3}$ & \\
\hline & Parameter & RSD \% & RC\% & $\mathrm{RE} \%$ & Con. found \\
\hline & Direct & 0.72 & 98.86 & -1.14 & $4.9430 \times 10^{-3}$ \\
\hline & SAM & 0.83 & 100.74 & 0.74 & $5.0368 \times 10^{-3}$ \\
\hline TRH-MIP1+TBP & MSA & - & 100.65 & 0.65 & $5.0327 \times 10^{-3}$ \\
\hline & & Stan & rd sample & $5 \times 10^{-4}$ & \\
\hline & Parameter & RSD \% & RC\% & $\mathrm{RE} \%$ & Con. found \\
\hline & Direct & 1.09 & 98.56 & -1.44 & $4.9278 \times 10^{-4}$ \\
\hline & SAM & 0.93 & 98.40 & -1.60 & $4.9201 \times 10^{-4}$ \\
\hline & MSA & - & 98.94 & -1.06 & $4.9472 \times 10^{-4}$ \\
\hline & & Stan & rd sample & $5 \times 10^{-3}$ & \\
\hline & Parameter & RSD $\%$ & RC\% & $\mathrm{RE} \%$ & Con. found \\
\hline & Direct & 2.18 & 100.89 & 0.89 & $5.0443 \times 10^{-3}$ \\
\hline & SAM & 0.56 & 99.74 & -0.26 & $4.9868 \times 10^{-3}$ \\
\hline TR-HCl-MIP2+ & MSA & - & 99.65 & -0.35 & $4.9823 \times 10^{-3}$ \\
\hline DOP (B1) & & Stan & rd sample & $5 \times 10^{-4}$ & \\
\hline & Parameter & RSD\% & RC\% & RE\% & Con. found \\
\hline & Direct & 1.42 & 101.4 & 1.4 & $5.0701 \times 10^{-4}$ \\
\hline & SAM & 0.6 & 99.30 & -0.70 & $4.9650 \times 10^{-4}$ \\
\hline & MSA & - & 101.21 & 1.21 & $5.0606 \times 10^{-4}$ \\
\hline & & Stan & rd sample & $5 \times 10^{-3}$ & \\
\hline & Parameter & RSD $\%$ & RC\% & $\mathrm{RE} \%$ & Con. found \\
\hline & Direct & 2.03 & 99.06 & -0.94 & $4.9529 \times 10^{-3}$ \\
\hline & SAM & 0.57 & 99.57 & -0.43 & $4.9784 \times 10^{-3}$ \\
\hline TRH-MIP2 + NB & MSA & - & 100.35 & 0.35 & $5.0174 \times 10^{-3}$ \\
\hline (B2) & & Stan & rd sample & $5 \times 10^{-4}$ & \\
\hline & Parameter & RSD \% & RC\% & $\mathrm{RE} \%$ & Con. founded \\
\hline & Direct & 1.92 & 98.63 & -1.37 & $4.9314 \times 10^{-4}$ \\
\hline & SAM & 0.84 & 98.61 & -1.39 & $4.9306 \times 10^{-4}$ \\
\hline & MSA & - & 101.44 & 1.44 & $5.0718 \times 10^{-4}$ \\
\hline
\end{tabular}

The results of commercial tramadol tablet content research using the three methods of analysis are listed in Table 8, with their statistical results listed in Table 9. 
Table 8. Results of analysis of different types of commercial tramadol tablets

\begin{tabular}{|c|c|c|c|}
\hline Membrane composition & & RH-MIP1+TEH & \\
\hline \multirow{2}{*}{ Pharmaceutical } & \multicolumn{3}{|c|}{ COLTRA 50 (Haryana, India) } \\
\hline & DM & SAM & MSAM \\
\hline Concentration (taken) M & \multicolumn{3}{|c|}{$5 \times 10^{-3}$} \\
\hline Conc. founded & $4.9171 \times 10^{-3}$ & $4.9217 \times 10^{-3}$ & $5.0765 \times 10^{-3}$ \\
\hline Recovery \% & 98.34 & 98.43 & 101.53 \\
\hline RE\% & -1.66 & -1.57 & 1.53 \\
\hline RSD \% & 1.24 & 1.9 & - \\
\hline Concentration (taken) M & \multicolumn{3}{|c|}{$5 \times 10^{-4}$} \\
\hline Conc. founded & $4.8920 \times 10^{-4}$ & $5.1012 \times 10^{-4}$ & $5.0860 \times 10^{-4}$ \\
\hline Recovery \% & 97.84 & 102.02 & 101.72 \\
\hline RE\% & -2.16 & 2.02 & 1.72 \\
\hline RSD \% & 1.62 & 1.46 & - \\
\hline Membrane composition & \multicolumn{3}{|c|}{ TRH-MIP1+TBP } \\
\hline Pharmaceutical & \multicolumn{3}{|c|}{ Haryana, India } \\
\hline Concentration (taken) M & \multicolumn{3}{|c|}{$5 \times 10^{-3}$} \\
\hline Conc. founded & $4.9157 \times 10^{-3}$ & $5.0850 \times 10^{-3}$ & $5.0837 \times 10^{-3}$ \\
\hline Recovery \% & 98.31 & 101.70 & 101.67 \\
\hline RE\% & -1.69 & 1.70 & 1.67 \\
\hline RSD \% & 0.77 & 1.29 & - \\
\hline Concentration (taken) M & \multicolumn{3}{|c|}{$5 \times 10^{-4}$} \\
\hline Conc. founded & $5.1099 \times 10^{-4}$ & $5.0998 \times 10^{-4}$ & $5.0955 \times 10^{-4}$ \\
\hline Recovery \% & 102.2 & 102 & 101.91 \\
\hline RE\% & 2.2 & 2 & 1.91 \\
\hline RSD\% & 0.77 & 1.44 & - \\
\hline
\end{tabular}

*each measurement was repeated three times

\section{CONCLUSION}

Electrodes based on a molecular imprinted polymer for tramadol $\mathrm{HCl}$ were prepared using two different monomers and plasticizers. The values of Nernstian slope research indicate that the tramadol drug is bonded to the polymer by two covalent bonds. No interference of amino acids response was seen in the tramadol determination, and excellent results for the determination of tramadol in pharmaceutical samples were indicated. The recovery of synthetic tramadol solutions ranged from 88 to 102 .

\section{REFERENCES}

1. Doris W, MLS M, Sweetman SC. Martindale,the Complete Drug Reference, 33rd ed., Pharmaceutical Press. J Med Libra Assoc. 2012;100:2.

2. Saman A, Majid A, S. Rezvaneh S, Synthesis and characterization of molecularly imprinted polymer for controlled release of tramadol. Central Eur J Chem. 2010;8:3.

3. Saman D, Majid A, Seyed A. Preparation and utilization of a molecularly imprinted polymer for solid phase extraction of tramadol. Cent Eur J of Chem. 2010;8:4

4. Abdellatef $\mathrm{H}$. Kinetic spectrophotometric determination of tramadol hydrochloride in pharmaceutical formulation. J. Pharm. Biomed. Anal. 2002;29:5

5. Siva K, Kumar N, Vijai A, Akelesh A. Spectrophotometric methods for simultaneous estimation of aceclofenac and tizanidine. Int $J$ of Pharmtech Res. 2010;2:1.
Table 9. Statistic results for commercial tramadol tablets using the three methods of analysis

\begin{tabular}{|c|c|c|c|}
\hline Membrane composition & & TRH-MIP2+DOF & \\
\hline \multirow{2}{*}{ Pharmaceutical } & \multicolumn{3}{|c|}{ COLTRA 50 (Haryana, India) } \\
\hline & DM & SAM & MSAM \\
\hline Concentration (taken) M & \multicolumn{3}{|c|}{$5 \times 10^{-3}$} \\
\hline Conc. founded & $4.9161 \times 10^{-3}$ & $5.1086 \times 10^{-3}$ & $5.0935 \times 10^{-3}$ \\
\hline Recovery \% & 98.32 & 102.17 & 101.87 \\
\hline RE\% & -1.68 & 2.17 & 1.87 \\
\hline RSD \% & 1.01 & 1.54 & - \\
\hline Concentration (taken) M & \multicolumn{3}{|c|}{$5 \times 10^{-4}$} \\
\hline Conc. founded & $4.8975 \times 10^{-4}$ & $4.9248 \times 10^{-4}$ & $5.0925 \times 10^{-4}$ \\
\hline Recovery \% & 97.95 & 98.50 & 101.85 \\
\hline RE\% & -2.05 & -1.50 & 1.85 \\
\hline RSD \% & 0.66 & 0.89 & - \\
\hline Membrane composition & \multicolumn{3}{|c|}{ TRH-MIP2+NB } \\
\hline Pharmaceutical & \multicolumn{3}{|c|}{ COLTRA 50 (Haryana, India) } \\
\hline Concentration (taken) M & \multicolumn{3}{|c|}{$5 \times 10^{-3}$} \\
\hline Conc. founded & $5.0787 \times 10^{-3}$ & $5.0834 \times 10^{-3}$ & $5.0740 \times 10^{-3}$ \\
\hline Recovery \% & 101.57 & 101.67 & 101.48 \\
\hline RE\% & 1.57 & 1.67 & 1.48 \\
\hline RSD \% & 1.4 & 1.27 & - \\
\hline Concentration (taken) M & \multicolumn{3}{|c|}{$5 \times 10^{-4}$} \\
\hline Conc. founded & $4.9034 \times 10^{-4}$ & $5.0761 \times 10^{-4}$ & $5.1056 \times 10^{-4}$ \\
\hline Recovery \% & 98.07 & 101.52 & 102.11 \\
\hline RE\% & -1.93 & 1.52 & 2.11 \\
\hline RSD\% & 1.4 & 1.2 & - \\
\hline
\end{tabular}

*each measurement was repeated three times.
6. Hisham E Magda M, Heba M, Magda M. Spectrophotometric and spectrofluorimetric methods for analysis of tramadol, acebutolol and dothiepin in pharmaceutical preparations. Spectrochimica Acta Part A: Mol and Biom Spect. 2006;65:5.

7. Pedersen RS, Broesen K, Nielsen F. Enantioselective HPLC method for quantitative determination of tramadol andO-desmethyltramadol in plasma and urine. Appl to Clin Studies. 2003;57:5.

8. Omnia A, Mervat M. Development and Validation of a Spectrophotometric Method for the Determination of Tramadol in Human Urine Using Liquid-Liquid Extraction and Ion Pair Formation. Int J of Instr Sci. 2012;1:3.

9. 9-Augustin C, Daniela M, Manuela C, Maria D, Camil V. Optimized HPLC method for tramadol and O-desmethyl tramadol determination in human plasma. J. Biochem. Biophys. Methods. 2008;70:1.

10. Valli A, Polettini A, Papa P Montagna,M. Ther. Drug Monit. 2001;23.

11. Sharma N, Sanyal M, Shrivastav P. An accurate, rapid and sensitive determination of tramadol and its active metabolite O-desmethyltramadol in human plasma by LC-MS/MS. J Pharm Biomed Anal. 2009;49:2.

12. Omnia A, Mervat M. Development and Validation of a Spectrophotometric Method for the Determination of Tramadol in Human Urine Using Liquid-Liquid Extraction and Ion Pair Formation. Int J of Instr Sci. 2012;1:3.

13. Damiani P, Bearzotti M, Cabezón MA. Spectrofluorometric determination of ibuprofen in pharmaceuticalformulations. J Pharm Biomed Anal. 2001;25:3.

14. Sara A, Hisham A, Memo H, Mohamed N. Spectrophotometric, atomic absorption and conductometric analysis of tramadol hydrochloride. Chem Ind and Chem Quar. 2011;17:3. 
15. Zhong GA. Confirmatory Test for Zinc.Phys. Test. Chem. Anal. 2003;39:2.

16. Huang LC, Xiu R, Liu YZ, Meng CY, Li JC. Martindale: The Complete Drug Reference. J Med Libr Assoc. 2012;100:1.

17. 17 Sara M, Anis M, Hosny H, Abdellatef N. Spectrophotometric atomic absorption and conductometric analysis of tramadol hydrochloride. Chem. Ind. Chem. Eng. Q. 2011;17:3.

18. Abu-Shawish $\mathrm{H}$ el al. Optimization of tramadol-PVC membrane electrodes using miscellaneous plasticizers and ion-pair complexes. Mat Sci and Eng. 2011;31:2.

19. Abu-ShawishH, Abu Ghalwa N, Zaggout F, Saadeh S, Al-Dalou A, Abou Assi A. Improved determination of tramadol hydrochloride in biological fluids and pharmaceutical preparations utilizing a modified carbon paste electrode. Bioch Eng J. 2010;48:2.

20. Mohammad R, Taherehsadat R, Farnoush F, Siavash R, Parviz N. Application of a New Tramadol Potentiometric Membrane Sensor as a Useful Device for Tramadol Hydrochloride Analysis in Pharmaceutical Formulation and Urine. Curr Pharm analysis. 2007;5:1.

21. 21.Hassan A, Parviz N, Soraia M. Application of Novel Praseodymium (III) PVC-Membrane Electrode for Determination of $\operatorname{Pr}(\mathrm{III})$ Ions in Soil and Sediment Samples. Anal Lett. 2008;41:5.

22. Mohammad R, Bagher L, Parviz N. Determination of Midazolam by Potentiometric PVC membrane and MWCNTs based Carbon Paste Sensors. Int. J. Electrochem. Sci. 2012;7:1.

23. Mohammad G, Zahra M, Farnoush F, Parviz N. Samarium Microsensor: An Asymetric Potentiometric Membrane Sensor. Int. J. Electrochem. Sci. 2008;3:1.

24. Farnoush F, Bagher L, Mohammad R, Parviz N. PVC Membrane Sensor for Potentiometric Determination of Dicyclomine in Pharmaceutical Formulation. Int. J. Electrochem. Sci. 2012;7:1.
25. Hassan A, Mohammad A. Monitoring of iron (III) ions with a $\mathrm{Fe}^{3+}$-PVC membrane sensor based on 4, 4'-dimethoxybenzil bisthiosemicarbazone. J. Chil. Chem. Soc. 2009;54:2.

26. Singh A, Gupta V, Gupta B. Chromium(III) selective membrane sensors based on Schiff bases as chelating ionophores. Anal Chim Acta. 2007;28:1.

27. Farnoush F, Farhang M, Mohammad R, Parviz N. Determination of Ondansetron Hydrochloride by a Liquid Membrane Potentiometric Sensor Based on Room Temperature Ionic Liquids. Int. J. Electrochem. Sci. 2013;8:1.

28. Farnoush F, Meraj S, Morteza P. Symmetric and Asymmetric PVC Membrane Potentiometric Electrodes for the Analysis of Morphine Hydrochloride. Anal. Bioanal. Electrochem. 2016;8:8.

29. Al-BayatiYK. Al-jabari FI. Constraction of new selective electrodes for determination ibuprofen and their application in pharmaceutical samples. I.J.R.P.C. 2015;5:3.

30. Al-Bayati YK, Al-Saidi KH, Hussain MA. liquid selective electrodes for warfarin sodium based on poly(vinyl chloride) matrix membrane, Asian $\mathrm{j}$ of chem. 2016;28:9.

31. Al-Bayati YK, Karabat RR. potentiometric study of phenytoin -pvc membrane electrodes for determination of phenytoin in pharmaceutical preparations. J of Al-Nahrain Univ. 2016;19:1.

32. Al-Bayati YK, Al Khafaji IH. Synthesis of New Selective Electrodes for the Determination of Metronidazole Benzoate (MNZB) Based on a Molecularly Imprinted Polymer Combined With Poly Vinyl Chloride, I.J.C.R.G.G. 2017;10:3.

33. Natalia A, Andrey B. Application of Photocured Polymer Ion Selective Membranes for Solid-State Chemical Sensors. Chemosensors. 2015;3:2.

34. Harvey D. Modern Analytical Chemistry. J. Chem. Educ. 2000;77:6. 